\title{
Analyzing the Effect of Varying CBR on AODV, DSR, IERP Routing Protocols in MANET
}

\author{
Rajeev Paulus ${ }^{1}$, Reema Garg ${ }^{2}$, Tanbeer Kaur ${ }^{3}$, Shiv Veer Singh Rajput ${ }^{4}$ \\ ${ }^{\prime}$ (Assistant Professor, Department of Electronics and communication, SHIATS, Allahabad, U.P, INDIA) \\ ${ }^{2,3,4}$ (M.Tech Scholar, Department of Electronics and communication, SHIATS, Allahabad, U.P, INDIA)
}

\begin{abstract}
Mobile Ad Hoc Networks (MANET) are wireless networks which do not require any infrastructure support for transferring data packet between two nodes. Mobile ad-hoc network have the attributes such as wireless connection, continuously changing topology, distributed operation and ease of deployment. The mobile nodes perform both as a host and a router forwarding packets to other nodes. Routing in these networks is highly complex. It can be used for various applications areas as sensor applications, disaster management, conferences, rescue operations, military communications, hybrid wireless network architectures and wireless mesh networks and many more. Traditional routing mechanism and protocol of wired network are inapplicable to ad-hoc networks which initiated the need of a dynamic routing mechanism in ad-hoc network. This paper evaluates the performance of AODV, DSR (Reactive) and IERP (Hybrid) routing protocols with respect to varying Constant Bit Rate (CBR). A detailed simulation has been carried out in QualNet Simulator 6.1. The performance analysis is based on different network metrics such as Average End to End delay, Throughput, Average Jitter, Packet Delivery Ratio.
\end{abstract}

Keywords: AODV, DSR, IERP, Mobile Ad-hoc networks, QualNet 6.1

\section{Introduction}

Wireless networking is an emerging technology that allows users to access information and services electronically regardless of their geographic position. Mobile ad-hoc networks have been the focus of many recent research and development efforts. Wireless networks can be classified into two types one with infrastructure or other is without pre-specified infrastructure. In an ad hoc wireless network, the absence of any central coordinator or base station makes the routing a complex one, therefore the routing are done in a distributed manner in which all nodes coordinate to enable communication among them [1]. Each node function both as network router and as a network host. Networks using ad-hoc configuration concepts can be used in many military applications ranging from interconnected wireless access points to networks of wireless devices carried by individuals, e.g., digital maps, sensors attached to the body, voice communication, etc.

MANETs are composed of power limited devices with a limited transmission range, so in most cases they will not be able to communicate directly with the destination device. Thus, communication must be relayed through intermediate devices resulting in multiple-hops to the destination [2] [15]. A key issue in MANETs is the necessity that the routing protocols must be able to respond rapidly to topological changes in the network. A MANET can be used for both unicast and multicast type of communication. The overview of the paper is as: the introduction is given in Section I; The protocols which are taken for analysis in this paper are discussed in section II; Simulation setup is included in Section III. Results and discussion is specified in Section IV, section $\mathrm{V}$ is all about conclusion.

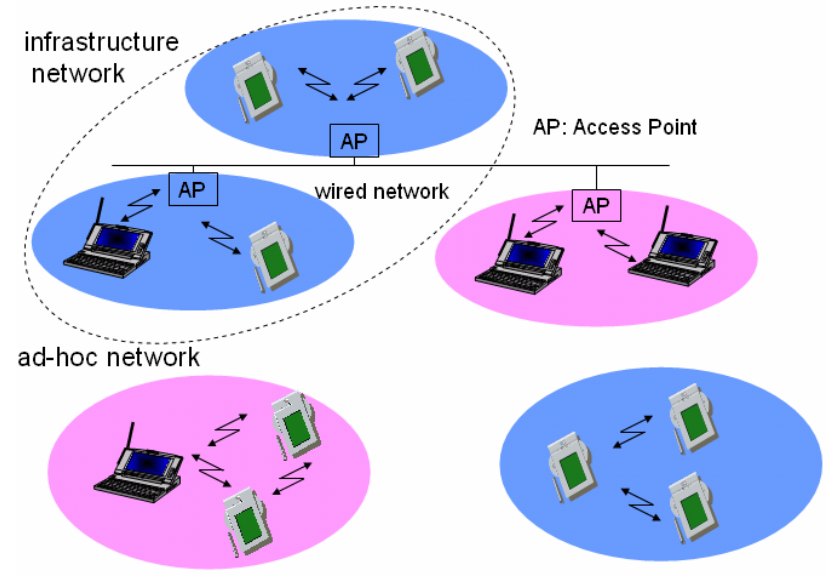

Fig.1 Infrastructure networks and ad hoc networks 


\section{Protocols Descriptions}

\subsection{Ad-Hoc Routing Protocols}

Various routing protocols have been developed for ad hoc mobile networks. Such protocols must deal with typical limitations of these networks which include dynamically changing topology, high power consumption, short battery lifetime, limited capacities, frequent disconnections, low communication bandwidth and high error rates. As figure 2 shows the categorization of Routing protocols into three categories namely, proactive and reactive \& hybrid [3] [11].

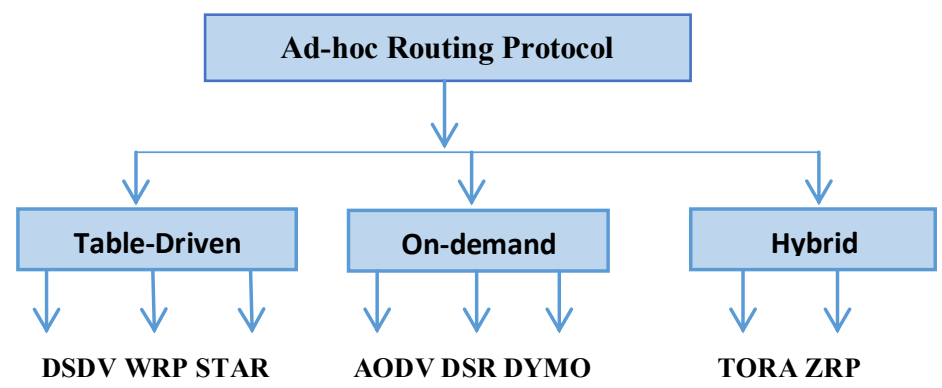

Fig 2.1. Categorization of ad-hoc routing protocol

\subsubsection{Ad-Hoc On Demand Distance Vector Routing Protocol (AODV)}

The Ad Hoc On-Demand Distance Vector routing protocol (AODV) is an improvement of the Destination-Sequenced Distance Vector routing protocol (DSDV) [4]. AODV, a reactive routing protocol initiate routing activities on an "on demand" basis. It is also called On-Demand Routing Protocol. It provides a quick adaptation to dynamic link condition, link fault, low processing and memory usage overhead [7][8]. It enables dynamic, self-ripting, multihop routing between participating mobile nodes wishing to establish and maintain an ad hoc network. AODV adopts traditional routing tables; one entry per destination which is in contrast to DSR that preserves multiple route cache entries for each destination. The AODV Protocol has a loop free routes in case of link breakage but unlike DSDV, it doesn't need global periodic routing. It is a flat routing protocol which does not need any central administrative system to handle the routing process. AODV uses a broadcast route discovery and maintenance algorithm [10].

\section{a) Path Discovery Process:}

When trying to send a message to a destination node without knowing an active route to it, the sending node will initiate a path discovery process. A route request message (RREQ) is broadcasted to all neighbors, which continue to broadcast the message to their neighbors and so on. The forwarding process is continued until the destination node is reached or until an intermediate node knows a route to the destination that is new enough. To ensure loop-free and most recent route information, every node maintains two counters: sequence number and broadcast id. The broadcast id and the address of the source node uniquely identify a RREQ message. An intermediate node can receive multiple copies of the same route request broadcast from various neighbors. In this case, if a node has already received a RREQ with the same source address and broadcast id, it will discard the packet without broadcasting it furthermore. To control the network-wide broadcasts of RREQ in the route discovery process, AODV uses an optimization technique of an expanding ring search. In this technique, source node starts discovering the destination using some initial time to live (TTL) value. If no reply is received within the discovery period, TTL value incremented by an increment value. This process will continue until the threshold value is reached. When an intermediate node forwards the RREQ, it records the address of the neighbor from which first packet of the broadcast is received, thereby establishing a reverse path. The response packet is sent by either the destination or a node that has a route to the destination. The route is established once the source node receives the RREP.

\section{b) Route Maintenance:}

AODV algorithm also includes the route maintenance facilities. If the source node moves, it is able to send a new RREQ packet to find a new route to the destination. If an intermediate node along the forward path moves, its upstream neighbor notices the move and sends a link failure notification message (RERR) to each of its active upstream neighbors to inform them of the erasure of that part of the route. The link failure notification is forwarded as long as the source node is not reached. After having learned about the failure, the source node may reinitiate the route discovery protocol. 


\subsubsection{Dynamic Source routing protocol (DSR)}

DSR is a source-routed on-demand routing protocol. The Dynamic Source Routing (DSR) [5] is another popular reactive routing protocol, like AODV nodes. The DSR protocol [7] [8] is a simple and efficient routing protocol designed specifically for use in multi-hop wireless ad-hoc networks of mobile nodes. A source node has the complete hop-by-hop route knowledge towards the destination and every generated data packet carries this information (source route) in its packet header. DSR is composed of the two mechanisms of Route Discovery and Route Maintenance [11]. The route discovery process is initiated when the source node doesn't find a route to the destination in its route cache or if the route has expired, it then broadcasts a RREQ. Any node that has a path to the destination in question can reply to the RREQ packet by sending a route reply (RREP) packet. The reply is sent using the route recorded in the RREQ packet. In case of broken link, route is maintained by using route error packets and acknowledgment.

\subsubsection{Interzone Routing Protocol (IERP)}

IERP is the reactive protocol component of the zone routing protocol (ZRP) [6]. As IARP finds routes within a zone, IERP is used to communicate between nodes of different zones and finds routes between nodes which are located at distances larger than the zone radius. The Route Discovery process is only initiated on demand. Operation of IERP - Firstly the source node checks whether the destination is within its routing zone. If it happens, the path to the destination is known and no further route discovery processing is required. On the other hand, if the destination is not within the source's routing zone then the source bordercasts a route request to all its peripheral nodes. Hence, to find the route, the process becomes slower, but the delay can be minimized by use of Bordercast Resolution Protocol [11]. It takes advantage of the fact that IARP knows the local configuration of a zone. Therefore a query is not submitted to all local nodes, but only to neighbor nodes. Moreover, even if the request comes from several nodes or peripheral nodes but then too a node does not send a query back to those nodes. IERP can use routing zones to automatically redirect data around failed links, once a route has been discovered [13] [14]. The below example shows the source node S sends packet to destination i.e. node $X$. This diagram has zone radius $r=2$. To check whether destination is within its zone, the node uses the routing table offered by IARP and if not found then route request is issued by IERP. Request is broadcasted to peripheral nodes. Fig. 2.1.3 shows that $\mathrm{S}$ bordercasts query to its border nodes G, J, I \& H. I is a border node which bordercasts again to its border nodes $\mathrm{Q}$ and $\mathrm{T}$. Finally, the route request is received by node $\mathrm{T}$, which can find the destination in its routing zone. Node $\mathrm{T}$ appends the path from itself to node $\mathrm{X}$ to the path in the route request. A route reply, containing the reversed path is generated and sent back to the source node [12].

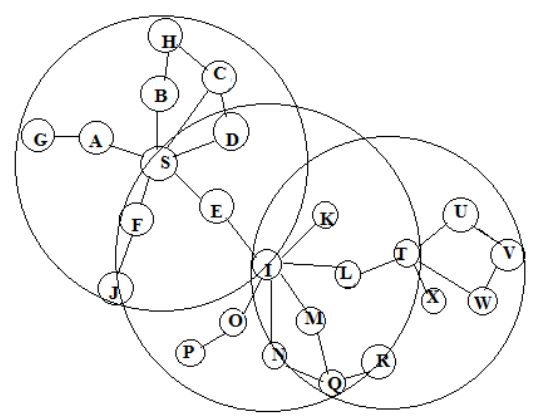

Fig.2.1.3 The routing zone of node S, I \& T

\section{Simulation Setup}

Simulation is carried out on QualNet 6.1 version [9]. The performance of Routing Protocols AODV, DSR and IERP is measured by analyzing the effect of varying CBR (constant bit rate) in MANET. Among various nodes application of Constant Bit Rate is applied. All the nodes in the depicted scenario are given a mobility using the protocol of Random waypoint mobility model. Simulation parameters are shown in table 1.With the help of simulation results we have analyzed Average Jitter, Packet delivery ratio, Throughput, and End-to-End delay for the given protocol. These performance metrics are defined below:

\subsection{Packet delivery ratio}

Packet delivery ratio is calculated by dividing the number of packets received by the destination through the number of packet originated by the application layer of the source (i.e. CBR source).

\subsection{Throughput}

The throughput is defined as the total amount of data a receiver receives from the sender divided by the time it takes for the receiver to get the last packet. The throughput is measured in bits per second (bit/s or bps). 


\subsection{Average End-to-End delay}

End-to-end delay indicates how long it took for a packet to travel from the CBR source to the application layer of the destination. It represents the average data delay an application or a user experiences when transmitting data.

\subsection{Average Jitter}

Jitter is the variation in the time between packets arriving, caused by network congestion, timing drift, or route changes. Jitter should be small for a routing protocol to perform better.

Table1. Parameters Values

\begin{tabular}{|l|l|}
\hline Simulation parameter & value \\
\hline Size & $900 \times 900 \mathrm{~m} 2$ \\
\hline Simulation time & $180 \mathrm{sec}$ \\
\hline No. of nodes & 150 \\
\hline Routing protocols & AODV,DSR,IERP \\
\hline Mobility model & RWP \\
\hline Max speed & $15 \mathrm{mps}$ \\
\hline Pause time & $20 \mathrm{sec}$ \\
\hline Pathloss model & Free space \\
\hline Shadowing model & lognormal \\
\hline No. of CBR & $3,6,9,12,15$ \\
\hline Packet generation & 4 packets per sec \\
\hline
\end{tabular}

\section{Results And Discussions}

Fig.5, shows that variation of throughput against No. of CBR, it can be observed that AODV is almost constant as compared to DSR and IERP. Throughput of IERP was firstly less than AODV but as no. of CBR increases, it increases. After that if the no. of CBR are increased, its value decreases and becomes minimum. DSR was same as AODV but by increasing no. of CBR, it decreases and after that while increasing no. of CBR, it becomes almost constant and is same as AODV.

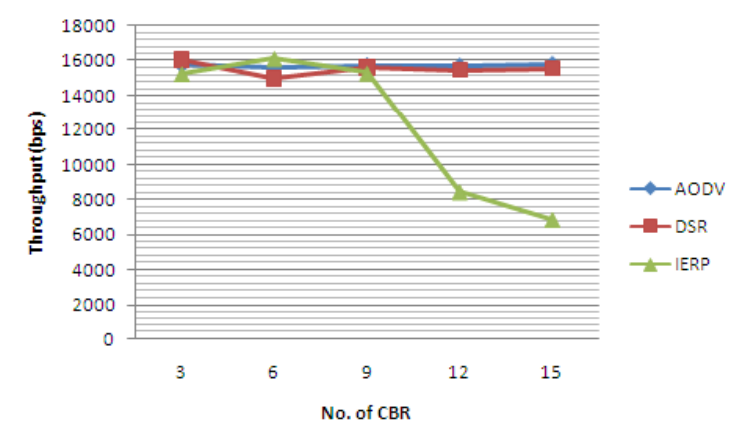

Fig.5 Throughput vs No. of CBR

Fig.6, shows that variation of average jitter against No. of CBR, it is observed that AODV and DSR has the lowest jitter and is same throughout as compared to IERP. Therefore AODV and DSR performs well. IERP jitter variation is greater than AODV and DSR. In IERP, with increase in no. of CBR, average jitter increases and at value 15 , its value is maximum. Hence, IERP performs poorly.

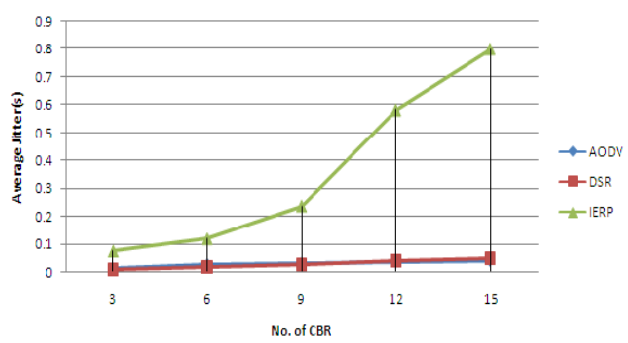

Fig.6 Average Jitter vs No. of CBR

Fig.7, shows the variation of average end to end delay against No. of CBR and it is observed that DSR has lowest value of average end-to-end delay with all most constant value. With increasing no. of CBR, average end to end delay of IERP increases and is maximum at value 15. 


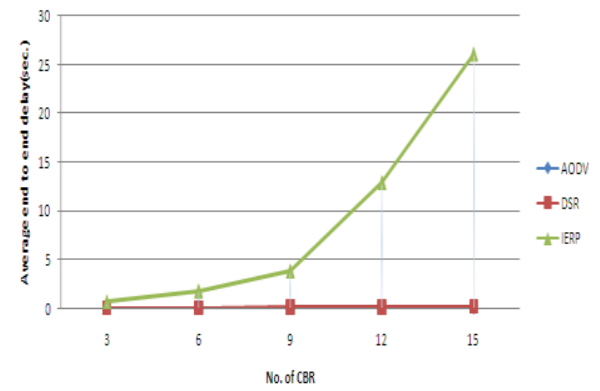

Fig.7 Average end-to-end delay vs. No. of CBR

Fig.8, shows the variation packet delivery ratio against no. of CBR and it is observed that for AODV packet delivery ratio is almost constant and is high for all the no. of CBR as compared to DSR and IERP. DSR has slightly greater PDR than IERP but at value 6, PDR decreases and then increases when there is increase in no. of CBR and becomes constant after that.

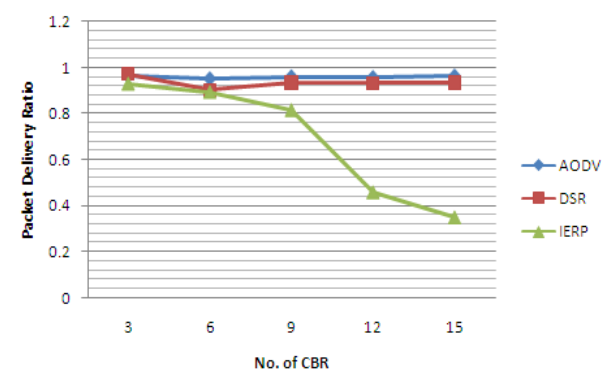

Fig.8 Packet delivery Ratio vs No. of CBR

\section{Conclusion}

This paper presents a performance comparison of AODV, DSR, IERP routing protocol for mobile adhoc networks with variable CBR. We measure End to End delay (s), Average Jitter (s), Throughput and Packet delivery ratio as performance metrics. Our simulation results shows AODV performance is best under all performance metrics. DSR throughput and packet delivery ratio is better than IERP. IERP shows the worst performance for average jitter and average end-to-end delay with the varying CBR. In future, this paper can be enhanced by analyzing the other MANET routing protocols under real-world scenarios.

\section{References}

[1] R. Paulus, P.D. Kumar, P.C. Philips, A. Kumar "Performance Analysis of Various Ad Hoc Routing Protocols in MANET using Variation in Pause Time and Mobility Speed", International Journal of Computer Applications (0975 - 8887) Volume 73- No.8, July 2013.

[2] P.K Maurya, Rajeev Paulus, A.K. Jaiswal, M. Srivastava , "Performance Analysis of ZRP over AODV, DSR and DYMO for MANET under Various Network Conditions using QualNet Simulator" Volume 66-No.17, IJCA (0975 - 8887), March. 2013

[3] Syed Basha Shaik , Prof. S. P. Setty ," Performance Comparison of AODV, DSR and ANODR for Grid Placement Model" International Journal of Computer Applications (0975 - 8887) Volume 11-No.12, pp 6-9, December 2010.

[4] Perkins, E. Belding-Royer, and S. Das, “Ad hoc On-Demand Distance Vector (AODV) Routing, "draftietf-manet-aodv-13.txt, Feb. 2003.

[5] J.Broch, D. Jhonson, and D.Maltz, "The dynamic source routing protocol for mobile adhoc networks for IPv4" IETF RFC 4728, Feb 2007.

[6] Z J. Haas, M. R. Pearlman, and P. Samar, "The Zone Routing Protocol (ZRP) for Adhoc Networks", draft-ietf-manet-zone-zrp04.txt.July 2002.

[7] S.R.Das, C.E.Perkins and E. M. Royer, 2000. "Performance Comparison of Two On-Demand Routing Protocols for Ad-Hoc Networks," In Proceedings of INFOCOM 2000.

[8] S. R. Raju and J.Mungara "Performance Evaluation of ZRP over AODV and DSR in Mobile Adhoc Networks Using Qualnet" ISSN 1450-216X Vol.45 No.4 (2010), pp.651-667, European Journal of Scientific Research, 2010.

[9] The QualNet simulator, www.scalablenetworks.com.

[10] C.E. Perkins and E.M. Royer, "Ad-hoc On-Demand Distance Vector Routing", Proceedings of 2nd IEEE Workshop, Mobile Computing System Applications, pp:90-100, 1999.

[11] K. Suresh and K. Jogendra "Comparative Performance Study of Zone Routing Protocol over AODV and DSR Routing Protocols on Constant Bit Rate (CBR)" Volume 45-No.4, IJCA (0975 - 8887), May 2012.

[12] Nicklas Beijar Networking Laboratory, Helsinki University of Technology "Zone Routing Protocol (ZRP)".

[13] Zygmunt J. Haas, Marc R. Pearlman,Prince Samar, “The Intrazone Routing Protocol (IARP) for Ad Hoc Networks, ” draftietfmanet-zone-iarp-01.txt, June 2001.

[14] Zygmunt J. Haas, Marc R. Pearlman,Prince Samar, “The Interzone Routing Protocol (IERP) for Ad Hoc Networks, ” draftietfmanet-zone-ierp 02.txt July 2002.

[15] M. Senthil Kumar, Dr. R. Asokan, "Impact of Node Density and Pause Time on the Performance of Ad Hoc Routing Protocols" GESJ: Computer Science and Telecommunications, No.4 (27) ISSN 1512-1232 40, 2010. 